\title{
A Framework for Comparative Evaluation of the Life Cycle Sustainability of Modular and Conventional Buildings
}

\author{
Mohammad KAMALI ${ }^{1}$ and Kasun HEWAGE ${ }^{1 *}$ \\ ${ }^{1}$ School of Engineering, University of British Columbia, Kelowna, BC, Canada \\ *Corresponding author’s e-mail: kasun.hewage@ubc.ca
}

\begin{abstract}
In recent decades, the construction industry has experienced the process of industrialization and off-site construction methods have been used as a substitute for their conventional on-site counterparts. Off-site construction is defined as a process, in which building elements and components are manufactured and preassembled off the construction site, in a factory environment, before their installation on the final project location. Modular construction is one of the main methods of off-site construction that can be applied to diverse types of buildings, ranging from a small residential building to a complicated commercial project. The published technical literature indicates that modular buildings offer numerous benefits that can effectively contribute to the sustainability in construction. However, there is a lack of comparative studies, which comparatively analyzed the life cycle sustainability performance of modular and conventional buildings. This paper proposes a life cycle sustainability assessment (LCSA) framework based on the analytic hierarchy process (AHP), which is one of the multicriteria decision making (MCDM) techniques. This framework evaluates and compares the life cycle sustainability of modular and conventional buildings by addressing all the key sustainability dimensions, i.e., environmental, economic, and social. Different components of the proposed framework and the potential outcomes of its application are presented in this paper.
\end{abstract}

\section{KEYWORDS}

Off-site construction; modular construction; life cycle sustainability performance; sustainability criteria

\section{INTRODUCTION}

On-site construction (also known as site-built or stick-built) refers to the conventional process of construction, in which a contractor constructs a building on the final project site after the design phase. Since the late 19th century, on-site construction has been the common construction method and nowadays it accounts for a significant portion of the housing industry (Zenga and Javor 2008). However, in the light of the industrialization of the construction process, the construction industry has experienced different construction methods during the past few decades. As a result, off-site construction methods have been used as a substitute for their conventional on-site counterparts. 
The off-site process of construction is significantly different than that of on-site. In the case of off-site construction, different elements and components of a building are first manufactured and preassembled, and then they are transported to the final project site and installed to form the building. Modular construction is one of the significant and rapidly growing off-site construction methods that is mainly used in North America, and a number of European and Asian countries (Annan 2008; Li et al. 2013). Modular buildings consist of one or more modules that are built and preassembled in an off-site fabrication center (i.e., factory environment), and all the mechanical, electrical, plumbing, and trim work (about $85 \%$ of the total construction phase) is completed there (O’Brien et al. 2000; Kawecki 2010). The modules are then transported to the final project site for installation on permanent foundations similar to those in on-site buildings (Cameron and Di Carlo 2007). The modular construction method can be applied to a wide range of building types, such as residential apartments, schools, hospitals, offices, etc. (Annan 2008).

A comprehensive literature review by the authors indicated that modular buildings offer numerous advantages that can effectively contribute to the sustainability in construction. One the most significant benefits of modular construction is time savings due to the fact that the construction of modules and site preparation activities occur simultaneously. In addition, higher productivity and workmanship, cost savings, better product control and quality, higher safety, reuse potential after the use phase, and fewer negative environmental impacts are the other most noticeable advantages of using modular construction (Zenga and Javor 2008; Li et al. 2013; O’Brien et al. 2000; Kawecki 2010; Cameron and Di Carlo 2007; Quale et al. 2012; Blismas et al. 2006; McGraw-Hill 2012; Gibb and Isack 2003; MBI 2012).

Because of the importance of the sustainable construction, it is imperative to comparatively assess the life cycle performance of different construction methods by addressing all the key sustainability dimensions, i.e., environmental, economic, and social. The published technical literature did not show numerous comparative life cycle studies that comprehensively analyzed the life cycle sustainability performance of modular and conventional buildings. The few published studies only address the environmental dimension of sustainability. Therefore, the primary objective of this paper is to develop an evaluation framework that is capable of comparatively assessing the life cycle performance of modular and conventional buildings with regard to the key sustainability dimensions.

First, the concept of the life cycle sustainability assessment of a product is briefly introduced. Then, the process of developing a conceptual framework for comparative evaluation of the life cycle sustainability of modular and conventional buildings and the potential advantages of its application are discussed. It should be mentioned that this paper is part of an ongoing comprehensive research project currently being conducted by the authors regarding the life cycle sustainability of modular buildings.

\section{LIFE CYCLE SUSTAINABILITY ASSESSMENT}

A building is regarded as a sustainable product only when all the key sustainability dimensions, i.e., environmental, economic, and social, are addressed and dealt with over its life cycle. However, the primary focus of most of the available sustainability assessment tools and 
studies is on environmental characteristics (Braganca et al. 2010). In order to assess the sustainability performance of a product, Kloepffer introduced the life cycle sustainability assessment (LCSA) concept. By using LCSA, product performance can be measured with regard to the key sustainability dimensions. The LCSA concept can be applied by the following framework (Kloepffer 2008; Finkbeiner et al. 2010):

$$
\mathrm{LCSA}=\mathrm{LCA}+\mathrm{LCC}+\mathrm{SLCA}
$$

where LCA is environmental life cycle assessment, LCC is life cycle costing, and SLCA is social life cycle assessment.

The primary purpose of the LCSA framework, similar to LCA, is not to decide if a product should be produced, but to assist stakeholders and decision makers in making more sustainable decisions, thus producing more sustainable products (Traverso et al. 2012). According to Swarr et al. (2011), one of the challenges faced by decision makers is to explore how separate environmental, economic, and social assessments can be used in practical situations to make trade-offs explicit.

\section{METHODOLOGY}

As mentioned above, this paper aims to introduce a conceptual LCSA framework to comparatively evaluate the life cycle performance of modular and conventional buildings. In order to do that, an appropriate evaluation framework is developed to capture a broad range of environmental, economic, and social impacts of both construction methods based on the construction industry experts' opinions. Therefore, the proposed framework will be capable of qualitatively assessing the extent to which modular and conventional buildings are sustainable.

The proposed LCSA framework is developed based on the analytic hierarchy process (AHP), which is used to aggregate the impacts of various sustainability criteria into a unified sustainability score. AHP is one of the widely used multi-criteria decision making (MCDM) techniques to solve complex decision making problems consisting of numerous parameters, i.e., various criteria (attributes) and few alternatives. Invented by Saaty (Saaty 1980), AHP is able to combine qualitative and quantitative criteria in a systematic decision making framework (Wedley 1990). AHP, indeed, is a systematic and step by step process, by which a subjective assessment of the parameters' relative importance is converted to a set of priority ratio scale and overall scores. In an AHP framework, the pairwise comparison method is used for determining the relative importance (weight) of a parameter, such as a criterion or an alternative, with regard to other parameters (Golden et al. 1989).

In the following sections, the steps required to construct the AHP-based LCSA framework appropriate for the sustainability comparison of modular and conventional buildings are discussed.

\section{AHP LEVELS' PARAMETERS}

The first critical step in developing an AHP-based framework is determining numerous 
parameters to be placed in different levels of the hierarchy, i.e., primary goal, criteria (attributes), and alternatives. In this LCSA framework, the hierarchy consists of four levels including:

(1) Primary Goal. The ultimate goal is sustainable building.

(2) Main Criteria. Three key sustainability dimensions, i.e., environmental, economic, and social, are considered as the main criteria and placed in the second level.

(3) Sustainability Criteria. Three sets of sustainability criteria, named sustainability performance indicators (SPIs), i.e., environmental SPIs, economic SPIs, and social SPIs, are identified as the parameters for this level.

(4) Alternatives. Modular and conventional construction methods are the alternatives; thus, they form the last level in the hierarchy.

Figure 1 illustrates the hierarchy of different levels and the contributing parameters in the LCSA framework. Note that En., Ec., and So., stand for the environmental, economic, and social dimensions of sustainability and $\mathrm{i}, \mathrm{j}$, and $\mathrm{k}$ are the number of selected SPIs for each of these sustainability dimensions, respectively. The process of selecting appropriate SPI sets for Level 3 is discussed below.

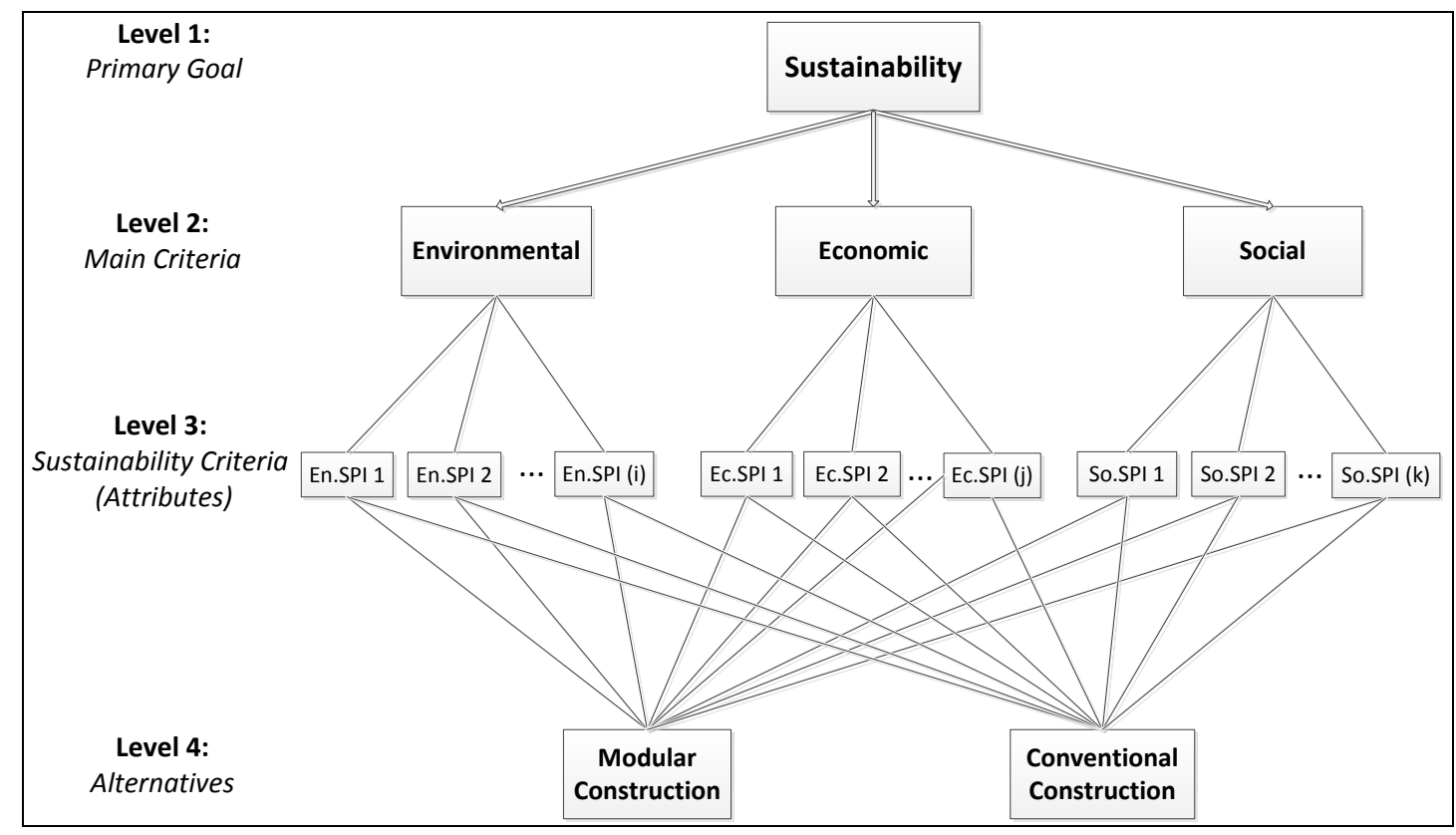

Figure 1. Hierarchy of parameters in the proposed LCSA framework

\section{SUSTAINABILITY PERFORMANCE INDICATOR SETS}

Selecting appropriate SPIs to be used as sustainability criteria in the framework (Level 3) is extremely important because the sustainability score of each alternative (i.e., construction methods) is significantly affected by them. In order to determine the most relevant SPI sets, two separate steps (Figure 2) will be taken as follows.

First, a broad list of criteria contributing to the life cycle sustainability of buildings is 
developed through conducting a content-analysis based literature review. Content analysis is a qualitative and systematic method to review and evaluate different documents. In other words, content analysis is the process of collecting and organizing information related to the primary research questions (Bowen 2009). In this study, two reference categories are used for review. The first reference category is those sustainable building rating systems that are intended to be used internationally or in North America, such as Leadership in Energy \& Environmental Design (LEED), Green Globes, among others. The second reference category comprises those published journal and conference articles in which the main focus is on sustainability of buildings and that provide sustainability performance criteria. Using the content analysis method, the common SPIs are prepared, modified, and combined to form a preliminary SPI set for each of the key sustainability dimensions.

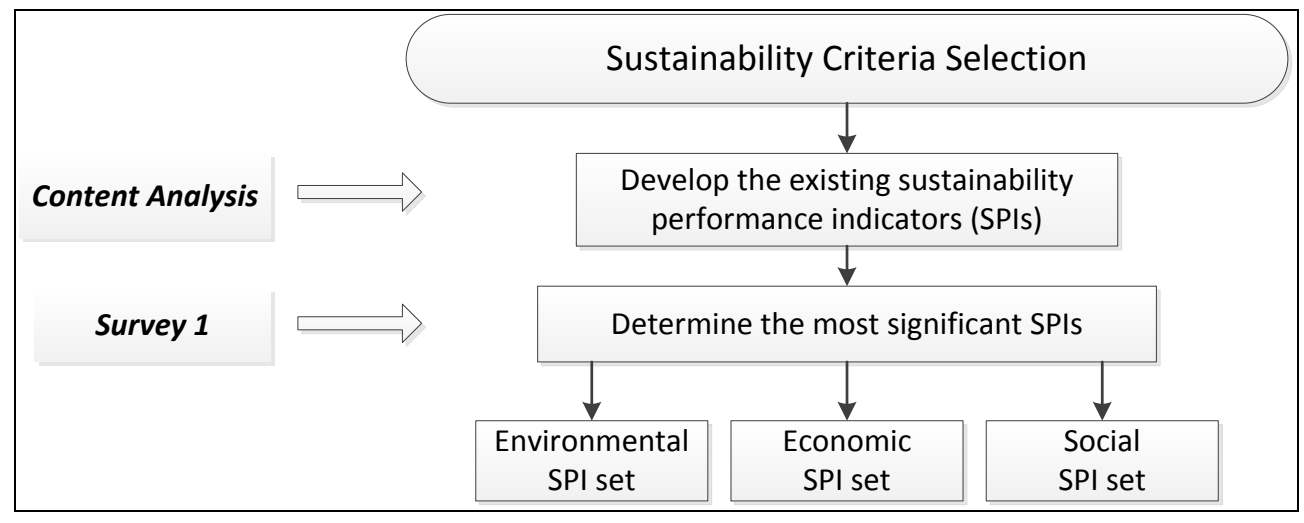

Figure 2. Steps needed to select the key sustainability criteria

By completing this step, 16 SPIs were eventually selected as the preliminary set related to the environmental dimension of sustainability. Energy performance, construction waste management, greenhouse gas emissions, and material consumption in construction are examples within the environmental SPI set. In addition, a total number of 9 SPIs and 12 SPIs were identified as the most commonly used criteria for buildings' life cycle economic and social performance assessment, respectively.

Second, to further refine the preliminary sets of SPIs, i.e., determination of the most significant SPIs when distinguishing the two construction methods, a questionnaire survey (Survey 1) has been designed and disseminated. The intended population of the survey is construction industry experts including engineers, architects, construction managers, developers, modular manufacturers, academic researchers, etc., who are experienced in both modular and conventional projects. It should be mentioned that this is an ongoing survey and its results will show the most distinguishing sustainability performance indicators (SPIs) between modular construction and its conventional counterpart.

\section{RELATIVE IMPORTANCE OF PARAMETERS}

After completing the identification of all the parameters (e.g., sustainability criteria) in the LCSA framework, the next step is to determine the relative importance of these parameters 
including criteria and alternatives. As mentioned earlier, the relative importance (weight) of a parameter is determined through performing pairwise comparison between all parameters located in a level in the hierarchy with regard to the parameters of the above level.

In order to do that, another survey (Survey 2) should be designed and conducted, based on the construction expert's feedback. By using a linguistic measure of importance in the survey, such as 9-point intensity scale, the respondent will be able to compare different parameters (Saaty 1990). Through performing this survey, the relative importance (weights) of different criteria and alternatives will be derived.

\section{SUSTAIABILITY SCORE}

Once the weights of all parameters are assigned, they can be aggregated to calculate the sustainability score, named the life cycle sustainability index (LCSI) in this paper, for each construction method alternative. LCSI is in the range of [0-1] and can be calculated for each alternative (i.e., modular or conventional) using:

$$
\begin{aligned}
& \mathrm{LCSI}=w_{E n .} \sum_{n=1}^{i}\left(w_{E n . S P I(n)} \times w_{A \rightarrow E n . S P I(n)}\right)+ \\
& w_{E c .} \sum_{n=1}^{j}\left(w_{E c . S P I}(n) \times w_{A \rightarrow E C . S P I}(n)\right)+w_{S o .} \sum_{n=1}^{k}\left(w_{S o . S P I}(n) \times w_{A \rightarrow \operatorname{So.SPI}(n)}\right)
\end{aligned}
$$

where $w_{E n}, w_{E c}$, and $w_{S o}$. are the weights of the environmental, economic, and social sustainability dimensions, respectively. Furthermore, $w_{E n . S P I(n)}, w_{E c . S P I}(n)$, and $w_{S o . S P I(n)}$ are the weights of the environmental SPI n, the economic SPI n, and the social SPI n, respectively. Moreover, $w_{A \rightarrow \operatorname{SPI}(n)}, \quad w_{A \rightarrow \operatorname{SPI}(n)}$, and $w_{A \rightarrow \operatorname{SPI}(n)}$ are the weights of the alternative A with respect to the environmental SPI n, economic SPI $n$, and social SPI n, respectively. By completing the process of calculating the life cycle sustainability indices, the alternative with the greater LCSI value will be considered as the more sustainable construction method.

\section{ANALYSIS AND DISCUSSION}

In order to evaluate and compare the life cycle sustainability of modular and conventional construction methods, AHP as a valuable decision making technique is used to develop an LCSA framework. In the proposed evaluation framework, the comparison of sustainability between the two construction methods is based on average opinions of the construction industry practitioners who have valuable experiences in both on-site and off-site construction projects. Therefore, AHP can be an effective technique that is able to aggregate their (qualitative) opinions on relative importance of parameters (e.g., sustainability criteria) into a tangible sustainability measure (i.e., LCSI). This is mainly due to the fact that in an AHPbased framework, the values of various quantitative criteria, such as greenhouse gas emissions, are not necessarily needed in order to determine the relative importance (weights).

The selected sustainability criteria, i.e., environmental SPIs, economic SPIs, and social SPIs, are a combination of quantitative and qualitative indicators (e.g., greenhouse gas emissions vs. residents' satisfaction). Therefore, AHP can be useful again as it is able to combine both qualitative and quantitative criteria in a systematic framework. 
It should be mentioned that in this LCSA framework, the determination of parameters' weights is subject to human subjectivity (i.e., construction experts' opinions). Thus, the decision makers should examine the sensitivity of the results (i.e., LCSI for each alternative) to different weighting schemes. In fact, to have a more precise comparison between the sustainability of the two construction methods (i.e., modular and conventional), this framework can be used by changing the method of assigning the weights to different parameters. That is, instead of using only people's opinions for determination of the relative importance of the parameters, which involves human subjectivity, the real values of quantitative criteria can be used for their weight determination. In addition, different weighting schemes recommended by academic/scientific organizations (e.g., US EPA) can be used. As mentioned earlier, this paper is part of an ongoing research project. Therefore, the abovementioned research gaps will be addressed in the future.

The potential advantages of the proposed LCSA framework are as follows:

(1) This framework introduces a systematic method for comparing the sustainability of modular and conventional buildings. However, it can be used to compare the sustainability of buildings that are built using different construction methods (e.g., precast and panelized). The framework can also be used to compare the sustainability of different building types including residential, commercial, and industrial.

(2) This framework addresses all the key sustainability dimensions (i.e., environmental, economic, and social), rather than evaluating only one sustainability dimension. For example, most of the studies in the literature addressed the environmental performance. Therefore, the obtained LCSI can be a more realistic and reliable measure of sustainability.

(3) Currently, there are many sustainability rating tools and systems that focus mostly on the environmental impacts of buildings, regardless of the construction method, and each one provides numerous performance criteria. This framework, in contrast, reduces the number of criteria by identifying the most distinguishing sustainability performance indicators (SPI sets) between modular and conventional buildings.

(4) Despite the many advantages of modular construction found in the literature, a comparative sustainability performance assessment of modular and conventional buildings over their life cycle is necessary. The results of this framework may assist different stakeholders including decision makers, policy makers, clients, developers, engineers, contractors, etc. with the selection of more sustainable construction methods in the future.

\section{CONCLUSIONS}

This paper introduces an AHP-based LCSA framework for comparative evaluation of the sustainability of modular and conventional buildings over their life cycle. In this framework, sustainability assessment is conducted based on the construction industry experts' feedback by addressing all the key sustainability dimensions, i.e., environmental, economic, and social. Selection of sustainability criteria (SPIs) related to each sustainability dimension was done through conducting a content-analysis based literature review and is currently being refined 
through a questionnaire survey. In addition, the relative importance of different parameters, such as sustainability criteria and alternatives, can be determined by performing another survey based on the pairwise comparison method.

The LCSA framework introduced in this paper can provide a deeper insight into the life cycle sustainability performance of modular construction compared to its conventional counterpart. Future work by the authors will use the proposed framework for developing a decision-support tool that can assist the construction industry practitioners in selecting more sustainable construction projects. The construction experts' feedback will be received through implementing the surveys to calculate the LCSI values for both construction methods. In addition, in order to make more precise comparisons, this framework will be used again for calculating the LCSI values by changing the methods of weight assignment to different parameters, as described in the previous section.

\section{REFERENCES}

Annan, C. (2008). “Applicability of traditional design procedures to modular steel building," thesis, presented to University of Western Ontario, ON, in partial fulfillment of the requirements for the degree of Doctor of Philosophy.

Blismas, N., Pasquire, C., and Gibb, A. (2006). "Benefit evaluation for off-site production in construction.” Constr. Manage. Econ., 24(2), 121-130.

Bowen, G. A. (2009). "Document analysis as a qualitative research method.” Qual. Res. J., 9(2), 27-40.

Braganca, L., Mateus, R., and Koukkari, H. (2010). "Building sustainability assessment.” Sustainability, 2(7), 2010-2023.

Cameron, P. J., and Di Carlo, N. G. (2007). "Piecing together modular: understanding the benefits and limitations of modular construction methods for multifamily development," thesis, presented to Massachusetts Institute of Technology, Cambridge, MA, in partial fulfillment of the requirements for the degree of Doctor of Philosophy.

Finkbeiner, M., Schau, E. M., Lehmann, A., and Traverso, M. (2010). “Towards life cycle sustainability assessment.” Sustainability, 2(10), 3309-3322.

Gibb, A., and Isack, F. (2003). "Re-engineering through pre-assembly: client expectations and drivers.” Build. Res. Inf., 31(2), 146-160.

Golden, B. L., Wasil, E. A., and Harker, P. T. (1989). The analytic hierarchy process: applications and studies, Springer-Verlag, Berlin.

Kawecki, L. R. (2010). "Environmental performance of modular fabrication: calculating the carbon footprint of energy used in the construction of a modular home," Thesis, presented to Arizona State University, Tempe, AZ, in partial fulfillment of the requirements for the degree of Doctor of Philosophy.

Kloepffer, W. (2008). "Life cycle sustainability assessment of products.” Int. J. Life Cycle Assess., 13, 89-95.

Li, H. X., Al-Hussein, M., Lei, Z., and Ajweh, Z. (2013). "Risk identification and assessment of modular construction utilizing fuzzy analytic hierarchy process (AHP) and simulation.” Can. J. Civ. Eng., 40(12), 1184-1195.

MBI. (2012). "Permanent modular construction.” Annual Report, Modular Building Institute, Charlottesville, Virginia.

McGraw-Hill. (2011). "Prefabrication and modularization: increasing productivity in the 
construction industry.” Report, McGraw-Hill Construction, New Orleans, LA.

O’Brien, M., Wakefield, R., and Belivean, Y. (2000). "Industrializing the residential construction site.” Report, Dep. of Housing and Urban Development, Office of Policy Development and Research, Washington, DC.

Quale, J., Eckelman, M. J., Williams, K. W., Sloditskie, G., and Zimmerman, J. B. (2012). "Construction matters: comparing environmental impacts of building modular and conventional homes in the United States.” J. Ind. Ecol., 16(2), 243-253.

Saaty, T. L. (1980). The analytic hierarchy process: Planning, priority setting, resource allocation. McGraw Hill, New York, NY.

Saaty, T. L. (1990). "How to make a decision: The analytic hierarchy process.” Eur. J. Oper. Res., 48(1), 9-26.

Swarr, E. T., Hunkeler, D., Klopffer, W., Pesonen, H. L., Ciroth, A., Brent, A. C., and Pagan, R. (2011). “Environmental life cycle costing: A code of practice.” Int. J. Life Cycle Assess., 16(5), 389-391.

Traverso, M., Finkbeiner, M., Jørgensen. A., and Schneider, L. (2012). "Life cycle sustainability dashboard.” J. Ind. Ecol., 16(5), 680-688.

Wedley, W. C. (1990). "Combining qualitative and quantitative factors - An analytic hierarchy approach.” Socioecon. Plann. Sci., 24(1), 57-64.

Zenga, M., and Javor, A. (2008). Modular homes: The future has arrived, Fideli Publishing, Paragon, IN. 